\title{
PILE RESPONSE DUE TO EARTHQUAKE INDUCED LATERAL SPREADING
}

\author{
Tanwar.H.K ${ }^{1}$, Biswas.S $\mathbf{S}^{2}$, Manna. $\mathbf{B}^{3}$ \\ ${ }^{I}$ B.Tech. Student, Department of Civil Engineering, IIT Delhi, New Delhi, tanwar_harish@yahoo.com \\ ${ }^{2}$ Research Scholar, Department of Civil Engineering, IIT Delhi, New Delhi, sanjit.jal@gmail.com \\ ${ }^{3}$ Assistant Professor, Department of Civil Engineering, IIT Delhi, New Delhi, bmanna@civil.iitd.ac.in
}

\begin{abstract}
Liquefaction assessment is a key aspect when the pile foundations are designed under seismic loading. The liquefaction associated with lateral spreading and flow failures that can affect the overall stability of the pile foundations. This study is emphasized to investigate the extent of the liquefaction zone and the effect of the liquefaction on the pile is also monitored by the means of estimating the maximum bending moment developed due to lateral ground displacement. The investigation site is located at I.I.T. Kharagpur Extension Centre, Block No. HC, Plot. 7, Sector-III, Salt Lake City, Kolkata, India. The diameter and pile shaft length are $0.45 \mathrm{~m}$ and $22 \mathrm{~m}$, respectively. The soil samples are collected from three boreholes located at the site of investigation and it is explored to a depth up to $30.45 \mathrm{~m}$ below the ground level. The boreholes reveal that the subsoil generally consists of six types of soil layers and the water table is at a depth of $1.25 \mathrm{~m}$ below the ground surface. A finite element model is simulated as per the field conditions using QUAKE/W (GeoStudio, 2007) to determine the depth of the liquefaction zone. The soil layers are idealized as 14 nodded rectangular elements. Initial static and dynamic analyses is performed by considering the linear elastic and equivalent linear models of soil using the earthquake history of peak acceleration of $0.16 \mathrm{~g}$. It is observed that the layer 1 susceptible to liquefaction due to high excess pore water pressure in that layer. Analytical study is carried out for the estimation of the maximum bending moment induced in the pile subjected to lateral ground displacement. The maximum deflection of the pile is also estimated due to the lateral ground displacement caused by the liquefaction.
\end{abstract}

Index Terms: Earthquake, Ground displacement, Lateral spreading, Liquefaction, Pile

\section{INTRODUCTION}

Experience from past earthquakes has demonstrated the vulnerability of structures to seismically induced ground deformation. Liquefaction and related phenomena have been responsible for tremendous amounts of damage in historical earthquakes around the world. From the last four a large number of investigations have been made for understanding the phenomenon of soil liquefaction potential.

Seismic response of pile foundations in liquefying soil is currently very popular area of research in geotechnical earthquake engineering. Some of the researchers were very interested to find out the performance and instability of pile foundation due to the liquefaction induced ground displacements (Tokimatsu and Aska, 1998; Bhattacharya, 2003). Observed pile damage and failure due to seismic excitation are necessitating an increased understanding through experimental study. Various researchers did several centrifuge model tests to monitor the response of the pile for seismically induced lateral spreading of single and multilayered soil (Abdoun, 1997; Brandenberg et al., 2005 Abdoun et al., 2003). The effect of lateral spreading of soil on model pile group was also observed by Imamura et al. (2004) with the help of centrifugal test. The study was also extended by performing shake table tests on the model pile as well as group pile (Cubrinovski et al., 2006; Towhata, 2006). Later the full scale pile response is monitor for controlled blast induced lateral spreading (Juirnarongrit et al., 2006).

Due to the difficulties in obtaining and testing undisturbed or representative samples from most potentially liquefiable sites, most of researchers preferred insitu testing for evaluating the liquefaction potential of soil (Ishihara, 1985; Seed, 1982). Many of the conducted experimental studies have been focused on lateral spreading loads due to a liquefying layer with or without an upper non-liquefiable stratum. Among all the methods available in the literature, the cyclic stress approach is very popular among consulting geotechnical engineers. This method was proposed by Seed et al. (1985) to find out the liquefaction zone by the use SPT N-values. In recent years, additional in-situ devices such as flat plate dialatometer, electrical measurement, shear wave velocity measurement etc. have been used by various researchers (Arulanandam and Muraleetharan, 1988; Arulmoli et al., 1985) to measure the liquefaction potential.

In the present study, the liquefaction zone of a site in Kolkata, India is determined using a finite element code considering 
two different soil models - linear and equivalent linear soil model. The ground displacement is determined at the surface after obtaining the liquefaction depth obtain from the finite element analysis. The maximum bending moment induced in the pile is determined and the maximum displacement of pile top is estimated due to that lateral spreading.

\section{SITE CHARECTERIZATION}

In this study, a site located at I.I.T. Kharagpur Extension Centre, Block No. HC, Plot. 7, Sector-III, Salt Lake City, Kolkata, India (Manna \& Baidya, 2009) is considered for the investigation. As per the seismic map of India the site falls under Seismic Zone III. Pile foundations are constructed at the site as a part of the structure. Necessary field and laboratory tests are carried out to determine the properties of soil. Disturbed and undisturbed soil samples are collected from the site up to the depth of $30 \mathrm{~m}$ from three boreholes located in the site. Laboratory tests are conducted on undisturbed and disturbed soil samples. The water table is found at the depth of $1.25 \mathrm{~m}$ below the ground level. In order to determine the $\mathrm{N}$ value, the SPT tests are conducted at different depths of the soil strata. Based on different laboratory observations and field test results the site soil is divided into six different layers. All the dimensions of the layers are shown in Fig -1 .

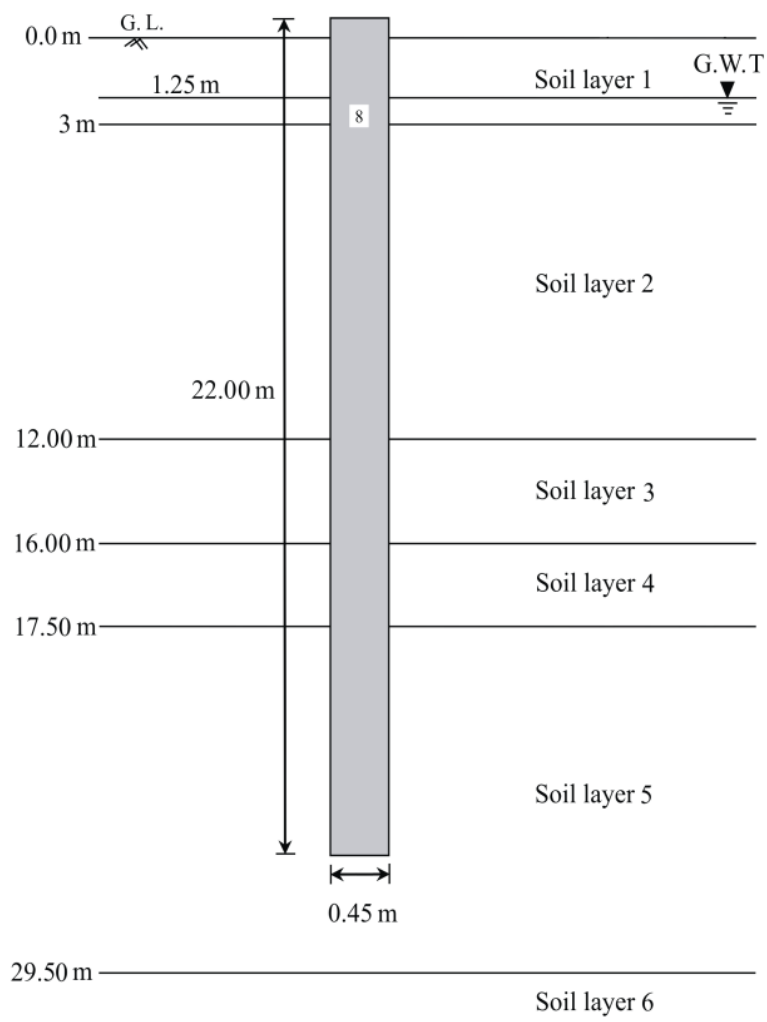

Fig -1: Dimensions of all the soil layers

\section{FINITE ELEMENT ANALYSIS}

QUAKE/W (GeoStudio 2007) is a geotechnical finite element software for the dynamic analysis of earth structures subjected to earthquake loading. The development of the excess porewater pressure in the soil due to earthquake loading can also be evaluated using this program. QUAKE/W uses the direct integration method to compute the motion and excess porewater pressures arising from inertial forces at user-defined time steps. Three consecutive soil models (a) linear-elastic model (b) equivalent linear model (c) effective stress nonlinear model are supported by QUAKE/W. In this study, the linear elastic and equivalent linear soil model are used.

\subsection{Analysis of Model}

A two dimensional finite element model is developed in QUAKE/W to find out the excess pore water pressure devolve in the soil and depth of the liquefiable soil layer under earthquake loading. The model consists of six soil layers as per the site characterization. The soil layers are discretized in 14 nodded rectangular elements.

To simulate the in-situ stress conditions initial static analysis is performed. The development of the initial pore water pressure condition is also done by initial static analysis. After the completion of the static analysis, the dynamic analysis is performed on the sane model with an assumed pick ground acceleration of $0.16 \mathrm{~g}$ (for Zone III). The complete response record of the model is monitored at the top and bottom of each layer.

The bottom boundary of the model is considered fixed against displacement and rotation in all directions. For the static analysis the displacement and rotation of the side soil boundary is allowed except horizontal displacement in $\mathrm{X}$ direction. But in the case of dynamic analysis only the vertical displacement in $\mathrm{Y}$ direction is restricted to allow the ground to sway from one side to other side as the earthquake accelerations is applied in horizontal direction.

\subsection{Input Data}

The response earthquake loading history is a very complex for the analysis. In order to simplify the response data, some of the modifications need to be done in the loading data for the finite element analysis. Some of the parameters are developed to satisfy the loading input format in QUAKE/W which represents the actual earthquake loading data.

The pore-pressures generated during earthquake shaking are a function of the number of loading cycles. Due to the undulation in the amplitude data for each cycle, a harmonic function needs to be developed which can be represented by an equivalent number of uniform cycle $(\mathrm{N})$ with specific shear stress amplitude $(\tau)$. According to Seed et al (1975a), the most common procedure is to set the uniform cyclic shear 
amplitude $(\tau)$ to $65 \%$ of the peak shear stress ( irregular shear stress time history. At the uniform cyclic shear stress, number of uniform cycle $(\mathrm{N})$ is also proposed by Seed et al. (1975b) for a specific earthquake magnitude.

During earthquake the shear stress is gradually build up in the soil which generates a sufficient excess pore-pressure for the liquefaction of soil. So it is essential to determine the number of cycles (NL) require to cause liquefaction for a particular soil under a particular set of stress conditions. To estimate the number of cycle (NL), a concept of cyclic stress ratios (CSR) is introduced which can be describe as follows

$$
C S R=\frac{q_{d}}{2 \sigma^{\prime}{ }_{v(\text { static })}}
$$

where, $q d$ is the cyclic deviator stress and $\sigma^{\prime} v$ (static) is the initial static effective vertical stress.

One of the purposes of the dynamic finite element analysis is to find the peak CSR values that develop during the earthquake. Based on the study of Seed and Lee (1965) the cyclic number function is developed from which the number of cycles (NL) is estimated at peak CSR. A typical curve of cyclic number functions for sand is shown in Fig -2 .

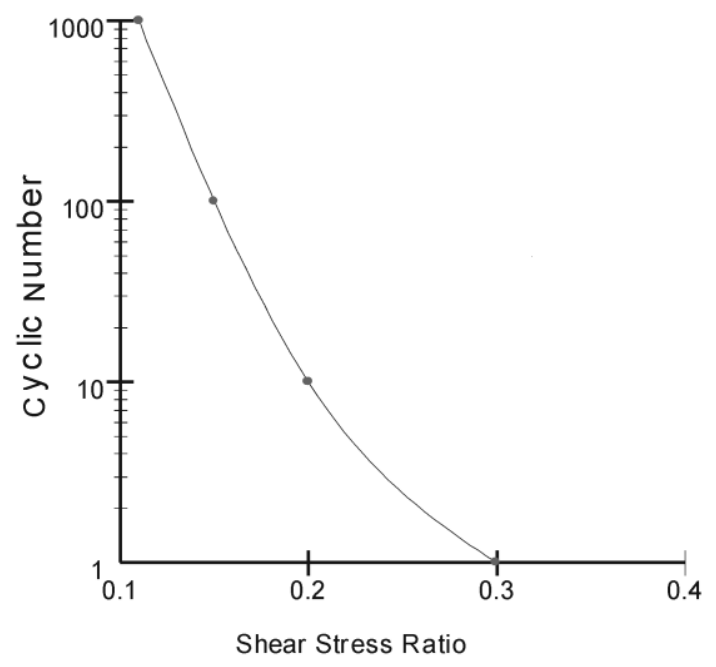

Fig -2: A typical cyclic number function curve

To compute the excess pore water pressure for the earthquake loading, the excess pore pressure ratio, $r_{u}$ (the ratio of the pore water pressure developed to the initial static vertical effective stress, $r_{u}=\Delta u / \sigma_{v}^{\prime}($ static $\left.)\right)$ is to be calculated. Based on the pore pressure function described by Lee and Albaisa (1974) and De Alba et al. (1975) the excess pore pressure ratio $\left(r_{u}\right)$ is calculated which is shown in Fig -3 .

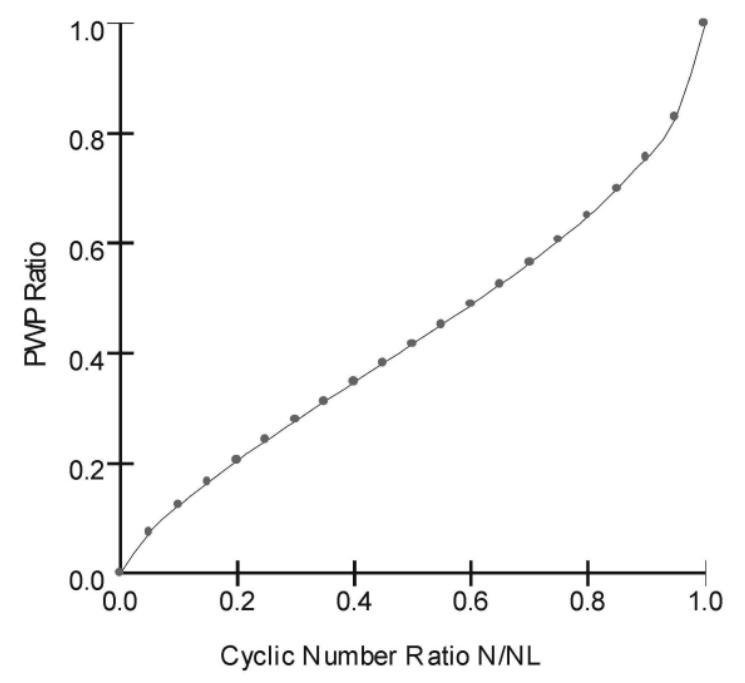

Fig -3: The excess pore water pressure function curve

\subsection{Correction Factors}

The magnitude of the confining stress has an effect on the generation of excesses pore-pressure which is depended on the cyclic stress ratio developed on the soil. To account for this, the idea of an overburden correction factor $(K s)$ is invoked. A typical overburden correction function is shown in Fig -4 which is used for finite element analysis.

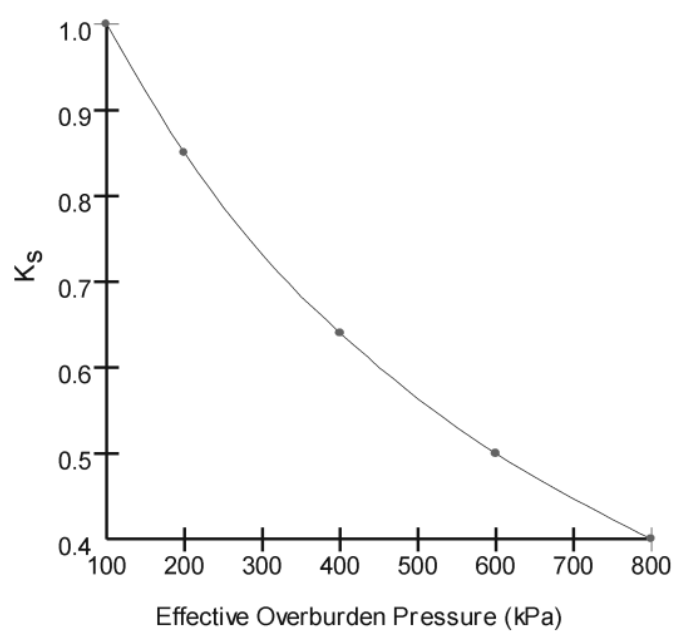

Fig -4: Overburden correction function curve

As the overburden stress has an influence on the liquefaction, the cyclic stress which is required to trigger liquefaction, is also influenced by the initial in-situ static shear stress. To consider this effect the shear stress correction factor $\left(K_{a}\right)$ is introduced. For finite element analysis two shear stress correction functions are assumed which is shown in Fig -5 and Fig -6. 


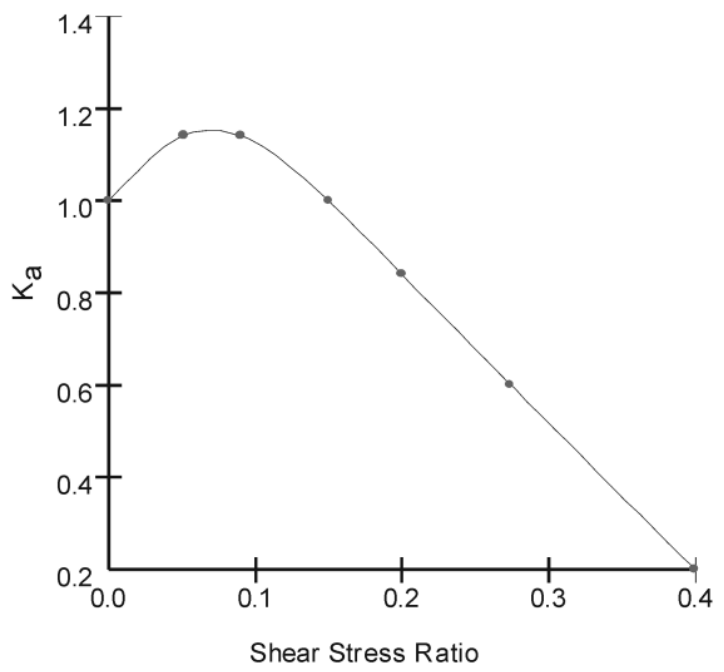

Fig -5: Shear stress correction function curve used for Layer I

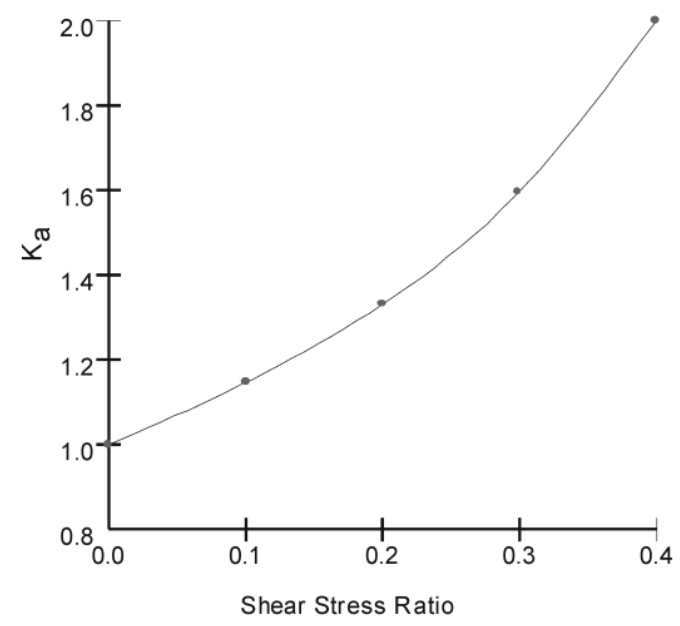

Fig -6: Shear stress correction function curve used for Layer 2, $3,4,5$ and 6

\subsection{Linear Elastic Model}

Linear elastic model is the simplest soil model where the soil stress $(\sigma)$ can be define by the following expiration

$$
\sigma=2 G(1+v) \varepsilon
$$

Where, $\mathrm{G}=$ shear modulus of soil, $v=$ Poission's ratio and $\varepsilon=$ strain develop in the soil.

Due to the simplicity of model, no iterative procedures are required in this numerical analysis and also the problem is not encountering any convergence issues. The material properties used for the analysis are shown in Table -1 . Considering a under damped system the Damping factor of the soil is assumed $(\mathrm{D}=0.1)$.

Table -1: Soil properties with depth used in linear elastic model

\begin{tabular}{|c|c|c|c|c|}
\hline $\begin{array}{c}\text { Layer } \\
\text { no. }\end{array}$ & Depth (m) & $\begin{array}{c}\mathrm{G} \\
\text { (kPa) }\end{array}$ & $\begin{array}{c}\text { Poisson's } \\
\text { ratio }\end{array}$ & $\begin{array}{c}\text { Unit wt. } \\
\left(\mathrm{kN} / \mathrm{m}^{3}\right)\end{array}$ \\
\hline 1 & 0 to 3 & 4000 & 0.25 & 17.8 \\
\hline 2 & 3 to 12 & 2963 & 0.35 & 17.9 \\
\hline 3 & 12 to 16 & 9259 & 0.35 & 18.9 \\
\hline 4 & 16 to 17.5 & 11111 & 0.35 & 18.8 \\
\hline 5 & 17.5 to 29.5 & 14815 & 0.35 & 20 \\
\hline 6 & 29.5 to 40 & 11111 & 0.35 & 18.8 \\
\hline
\end{tabular}

The linear elastic analysis is performed and the variation in excess pore water pressure and the cyclic stress ratio with depth are monitored at the top and bottom of the every layer which are shown in Fig -7 and Fig -8 respectively.

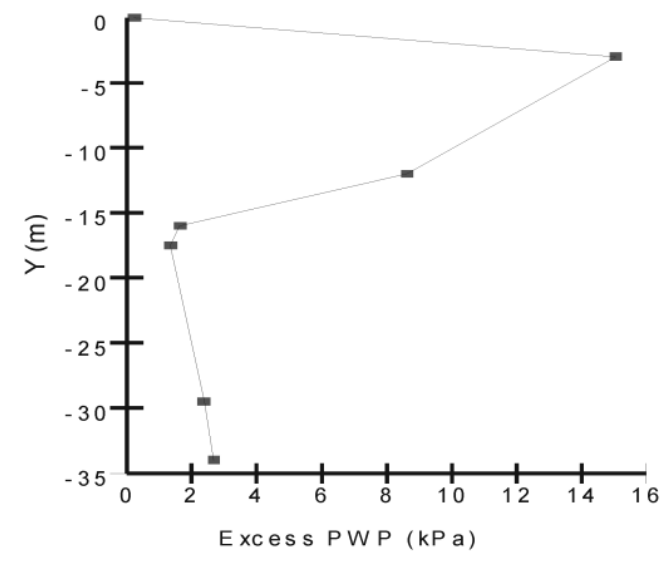

Fig -7: The variation in excess pore water pressure with depth (linear elastic model)

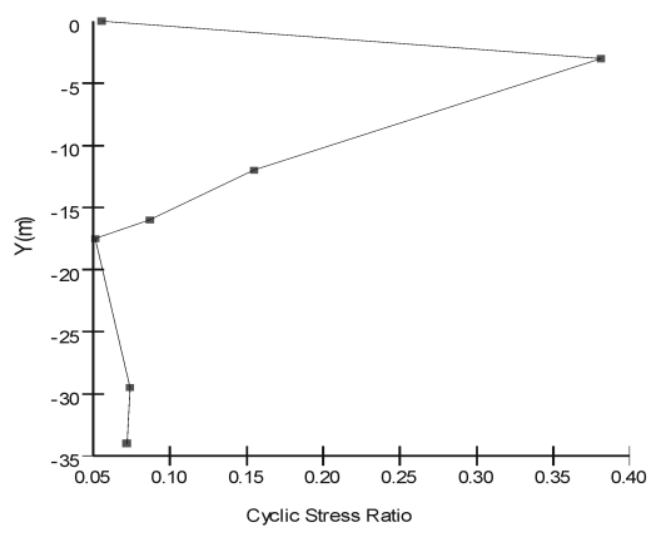

Fig -8: The variation in cyclic stress ratio with depth (Linear elastic model) 
From the both curve it is noted that the excess pore water pressure as well as the cyclic stress ratio is increased until it reaches its maximum value at the bottom of the first layer and then the values are drastically reduced. It implies that the liquefaction phenomenon is very prominent in the first layer of soil. A small increase of excess pore water pressure is found below $16 \mathrm{~m}$ depth.

\subsection{Equivalent Linear Model}

The equivalent linear model is very similar to the linear-elastic model. The only difference is that the soil stiffness is reduced according to the shear modulus reduction function at each iteration which is a very common and realistic phenomenon under earthquake loading. With the equivalent linear model, QUAKE/W modify the initial shear modulus of soil according to a specified shear modulus reduction function at each Gauss numerical integration point in each element. The process is repeated until the new shear modulus is within a specified tolerance. Material properties which are required in this model in addition of the properties used in the linear elastic model are shown in Table -2 .

Table -2: Additional Soil Properties with Depth Used in Equivalent Linear Elastic Model

\begin{tabular}{|c|c|c|c|c|c|}
\hline $\begin{array}{c}\text { Layer } \\
\text { no. }\end{array}$ & Depth (m) & $\begin{array}{c}\mathrm{c} \\
(\mathrm{kPa})\end{array}$ & $\begin{array}{c}\phi \\
\left({ }^{\circ}\right)\end{array}$ & PI & $\mathrm{K}_{\mathrm{o}}$ \\
\hline 1 & 0 to 3 & 0.3 & 22 & 49 & 0.625 \\
\hline 2 & 3 to 12 & 18 & 5 & 49 & 0.913 \\
\hline 3 & 12 to 16 & 63 & 7 & 26 & 0.878 \\
\hline 4 & 16 to 17.5 & 75 & 4 & 31 & 0.930 \\
\hline 5 & 17.5 to 29.5 & 10 & 35 & 49 & 0.426 \\
\hline 6 & 29.5 to 40 & 75 & 4 & 31 & 0.930 \\
\hline
\end{tabular}

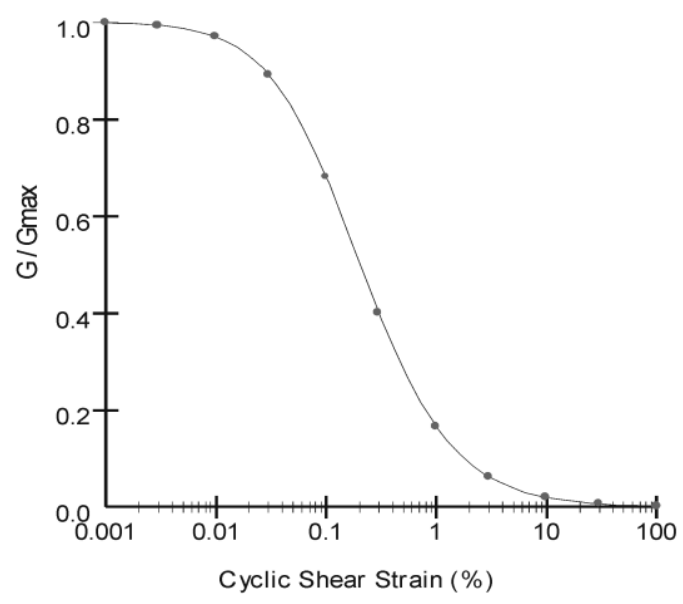

Fig -9: Shear modulus reduction function curve for Layer I
In the equivalent linear soil model, the G-reduction function is described as a ratio of initial soil shear modulus $(G)$ and the maximum shear modulus (Gmax). The cyclic shear strain of each element is calculated in the finite element analysis and the modified $G$ values are computed for a specified Greduction function for the each iteration. The expression for estimating the shear modulus reduction function mainly depends upon plasticity index and confining pressure. The shear modulus reduction function curve for each layer is shown in Fig -9 through Fig -14.

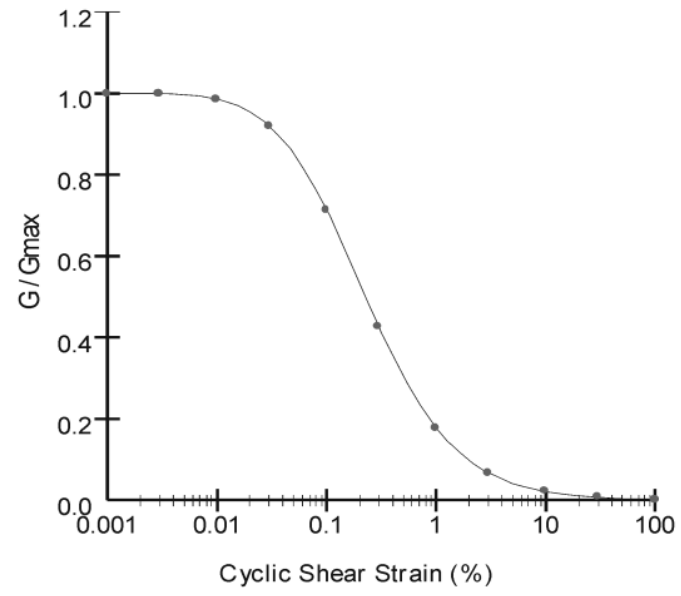

Fig -10: Shear modulus reduction function curve for Layer 2

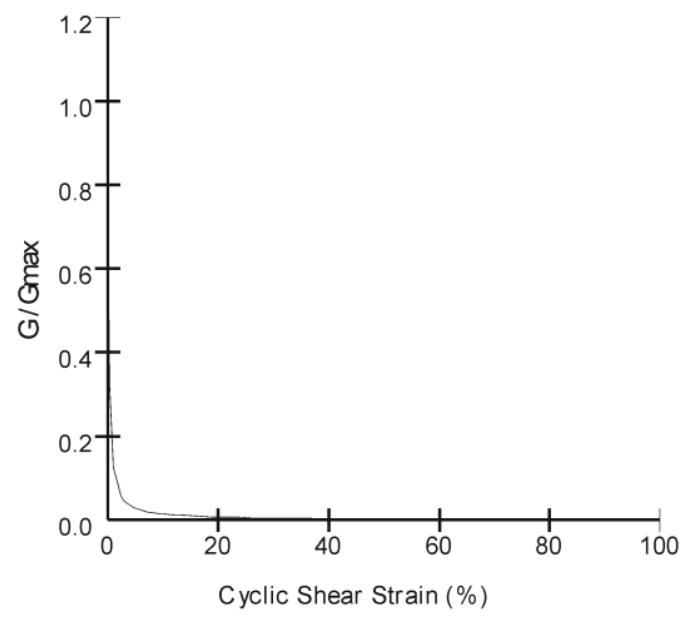

Fig -11: Shear modulus reduction function curve for Layer 3

After including all the soil properties the equivalent linear elastic analysis is performed and the change in excess pore water pressure and cyclic stress ratio with depth is determined as describe before which are shown in Fig -15 and Fig -16 respectively. 


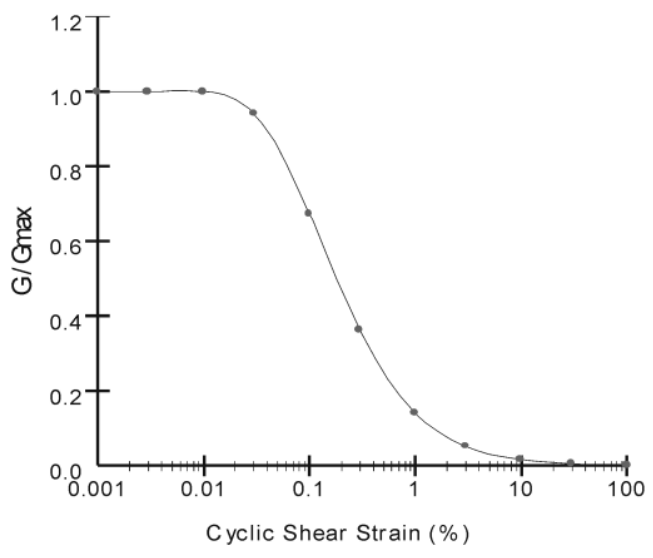

Fig -12: Shear modulus reduction function curve for Layer 4

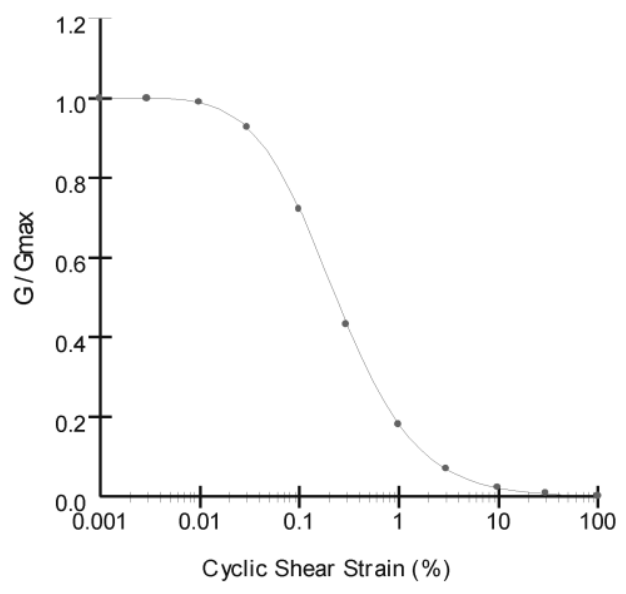

Fig -13: Shear modulus reduction function curve for Layer 5

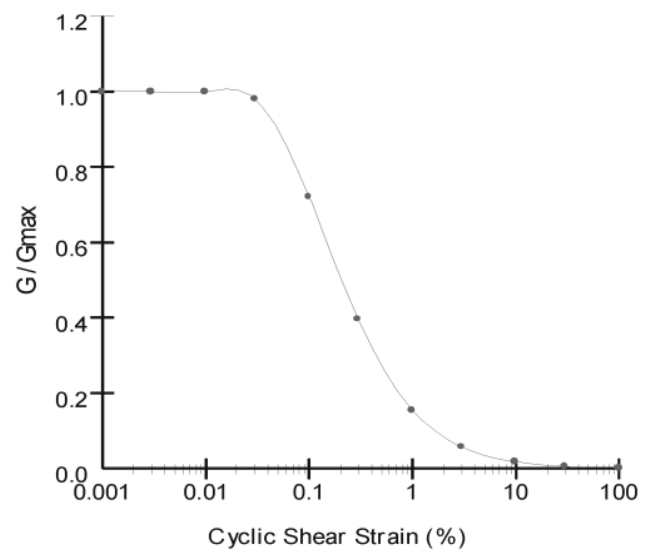

Fig -14: Shear modulus reduction function curve for Layer 6

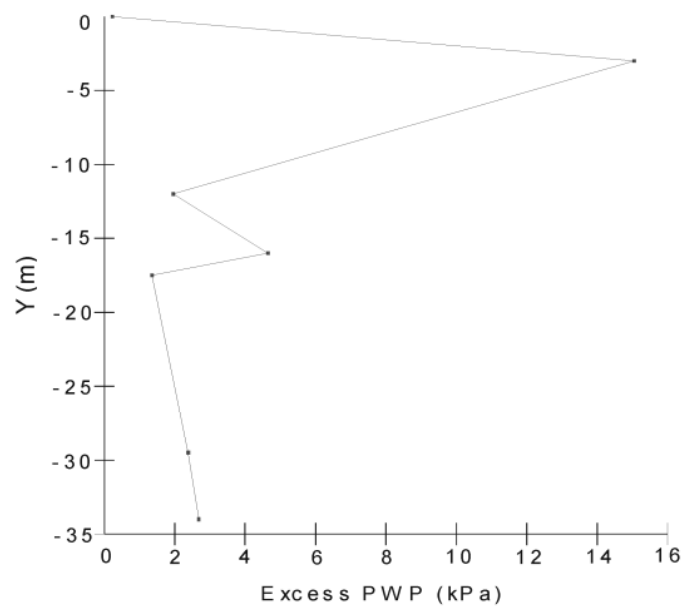

Fig -15: Variation in excess pore water pressure with depth (equivalent linear elastic analysis)

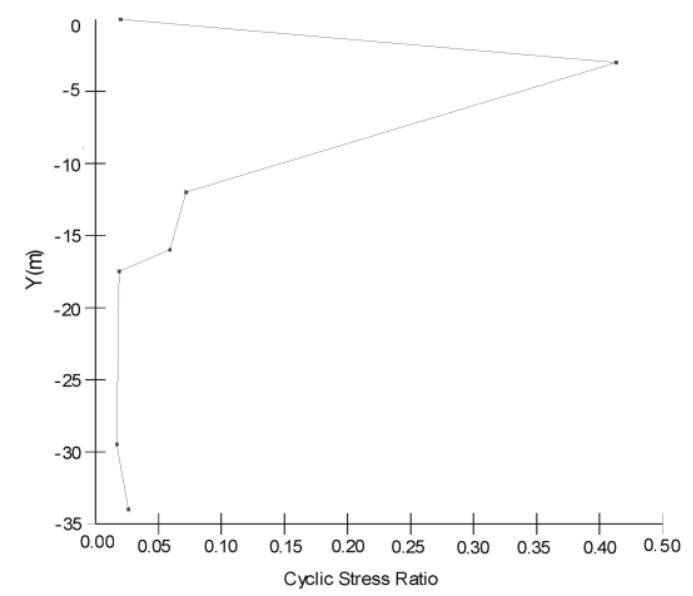

Fig -16: Variation in cyclic stress ratio with depth (equivalent linear elastic analysis)

From Fig -15 it is found that the excess pore water pressure achieved its maximum value at the bottom of the first layer but it not follows the same pattern of linear elastic results. In the case of the cyclic stress ratio the trend is found similar to linear elastic results but the magnitude is not same. It can be clearly observed that the possibility of liquefaction is found only in the first layer of soil.

\section{LATERAL SPREADING}

A linear analysis are carried out to estimate the maximum bending moment induced in piles subjected to the lateral ground displacement $\left(U_{g}\right)$ caused by liquefaction. Finally the pile top displacement $\left(U_{p}\right)$ is estimated by a simple spring 
mass beam model (Ishihara, 1999). The summary of all the results are shown in Table -3 .

\subsection{Pile Bending Moment}

Linear analyses are performed to find out maximum bending moment developed in the pile due to lateral displacement of ground by the use finite element analysis results. Soil displacement is assumed to be constant within the surface nonliquefiable layer and to decrease linearly within the liquefiable layer. The sequential analytical process is listed as follows

- The yield moment capacity of the embedded pile $\left(M_{e}\right)$ is estimated using pile section properties.

- The non-dimensional parameter $\beta$ is evaluated by the following equations

$$
\beta=\sqrt[4]{\frac{K h_{s} D}{4 E I}}
$$

where $K h_{s}=$ coefficient of horizontal sub-grade reaction of the surface layer, $D=$ the pile diameter and $E I=$ the flexural rigidity of the pile.

The value of $K h_{s}$ represents the reduction in soil stiffness which is due to the increase in pore water pressure in the soil.

- Dimensionless length of the pile above the base layer $(\beta l)$.

where the depth of base layer $(l)=3 \mathrm{~m}$.

- The ratio of thickness of the liquefiable layer to that of the entire upper layer $\left(h_{l} / L\right)$ is found out. where the thickness of the liquefiable layer $\left(h_{l}\right)=$ $1.5 \mathrm{~m}$ and the thickness of that entire upper layer $(L)$ $=3 \mathrm{~m}$.

- Now according to the methodology prescribe by Miura et al. (1991) the maximum bending moment $\left(M_{\max }\right)$ and the ratio of maximum bending strain to lateral defection $\left(\frac{M_{\max }}{E S} / \frac{U_{g}}{L}\right)$ is evaluated.

where $E=$ young's modulus and $S=$ the section modulus of pile.

- Finally the ground deformation at the surface $\left(U_{g}\right)$ is calculated.

\subsection{Pile Displacement}

The method of estimating of pile maximum defection is described by Ishihara (1999). A simple model is considered where a vertically placed beam representing the pile, is connected with a single spring which characterizes the response of the surrounding soil layers. It is assumed that liquefaction develops through the depth and lateral flow is generated in one direction. Ground deformation is represented by the cosine function with its maximum value $\mathrm{Ug}$ given on the surface. The outcome of this study is to calculate the value of the pile top displacement $\left(U_{p}\right)$ with the value of $U_{g}$ which is obtained before.

Table -3: Summary of all the analysis results

\begin{tabular}{|l|l|}
\hline Depth of liquefiable layer from G.L. & $1.5 \mathrm{~m}$ \\
\hline The maximum bending moment of pile & $413.04 \mathrm{kNm}$ \\
\hline Ground displacement at the surface & $0.0381 \mathrm{~m}$ \\
\hline The maximum displacement of pile top & $0.000381 \mathrm{~m}$ \\
\hline
\end{tabular}

\section{CONCLUSIONS}

In this study a finite element computer code QUAKE/W is used to predict the liquefaction zone of a site using both linear and equivalent linear soil model. The liquefaction depth of the model is predicted by monitoring the variation in excess pore water pressure and the cyclic stress ratio with depth. From the analysis results it is noted that the liquefaction phenomenon is dominate only in layer 1 . It is also observed that excess pore water pressure and cyclic stress ratio generated in layer 1 using linear elastic model is less as compared with equivalent linear model. It can be concluded that the equivalent linear model is more realistic than linear model. Using the liquefaction depth obtain from the finite element analysis the ground displacement is calculated at the surface. Due to that lateral spreading the maximum bending moment induced in the pile is also evaluated. Finally the maximum displacement of pile top is estimated. The value of maximum pile top displacement is found very low though the ground displacement is quite high.

\section{REFERENCES:}

[1]. Arulmoli, K., Arulanandan, K. and Seed, H. B. (1985). "New Method for Evaluating Liquefaction Potential," $J$. of Geotech. Eng. Div., ASCE., 111(1): 95-114.

[2]. Arulanandan, K. and Muraleetharan, K.K. (1988). "Level ground soil-liquefaction analysis using in-situ properties: I", $J$. of Geotech. Eng. Div., ASCE., 114(7): 753-770.

[3]. Abdoun, T. (1997). Modeling of seismically induced lateral spreading of multi-layered soil and its effect on pile foundations, Ph.D. Thesis, Rensselaer Polytechnic Institute, Troy, New York.

[4]. Abdoun, Tarek, Dobry, Ricardo, O'Rourke, Thomas D., and Goh, S. H. (2003). "Pile response to lateral spreads: Centrifuge modeling," J. Geotech. and Geoenviron. Eng., 129(10), 869-878.

[5]. Bhattacharya, S. (2003). Pile instability during earthquake liquefaction, Ph.D. thesis, University of Cambridge, Cambridge, U.K.

[6]. Brandenberg, S. J., Boulanger, R. W., Kutter, B. L., and Chang, D. (2005). "Behavior of pile foundations in laterally spreading ground during centrifuge tests." J. Geotech. Geoenviron. Eng., 131(11), 1378-1391.

[7]. Cubrinovski, M., T. Kokusho, and K. Ishihara (2006). "Interpretation from large-scale shake table tests on piles 
undergoing lateral spreading in liquefied soils," Soil Dyna. and Earthquake Eng., 26, 275-286.

[8]. De Alba, P., Chan, C. K. and Seed, H. B. (1975). "Determination of Soil Liquefaction Characteristics by LargeScale Laboratory Test," Report NO. EERC 75-14, Earthquake Engineering Research Center, University of California, Berkeley, California.

[9]. Ishihara, K. (1985). "Stability of natural deposits during earthquakes", Proc. of the 11th Int. Conf. on Soil Mech. and Foundation Eng., San Francisco, California, 1: 321-376.

[10]. Ishihara, K. (1999). "Lateral Flow-affected pile behaviour as interpreted by a simple model." 11th Asian Regional Conf., Seoul, Korea.

[11]. Imamura, S., T. Hagiwara, Y. Tsukamoto, and K. Ishihara (2004). "Response of pile groups against seismically induced lateral flow in centrifuge model tests," Soils and Foundations, 44(3), 39-55.

[12]. Juirnarongrit, Teerawut and Scott A. Ashford (2006). "Soil-pile response to blast-induced lateral spreading. II: analysis and assessment of the p-y Method," J. Geotech. and Geoenviron. Eng., Vol. 132(2), 163-172.

[13]. Kramer, S. L. (1996). Geotechnical Earthquake Engineering. Prentice-Hall, Englewood Cliffs, NJ.

[14]. Lee, K. L., and Albaisa, A. (1974), "Earthquake Induced Settlements in Saturated Sands," J. of Geotech. Eng. Div., ASCE., 100(GT4) :387-406.

[15]. Miura, F., Stewart, H.E. and O'Rourke, T.D. (1991). "The effects of liquefaction-induced lateral spreading on pile foundations", Soil Dyna. and Earthquake Eng., 10: 271-279.

[16]. Manna, B. and Baidya, D. K. (2009). "Vertical vibration of full-scale pile-analytical and experimental study." J. of Geotech. and Geoenviron. Eng., ASCE., 135(10): 1452-1461.

[17]. Seed, H. B., and Lee, K. L. (1965). "Studies of Liquefaction of Sands Under Cyclic Loading Conditions." Report TE-65-65. Department of Civil Engineering, University of California, Berkeley.

[18]. Seed, H.B., Idriss, I.M., Makidisi, F. \& Banerjee, N. (1975a). "Representation of Irregular Stress Time Histories by Equivalent Uniform Stress Series in Liquefaction Analyses." EERC 75-29. University of California, Berkeley.

[19]. Seed, H. Arango, I., and Chan, C.K. (1975b). Evaluation of soil liquefaction potential during earthquake, Report No. EERC 75-28, Earthquake Engineering Research Center, University of California, Berkeley, California.

[20]. Seed, H.B. and Idriss, I.M. (1982). "Ground motions and soil liquefaction during earthquakes," Mongraph No. 5, Earthquake Eng. Research Institute, Berkeley, California, $: 134$.

[21]. Seed, H.B., Tokimatsu, K., Harder, L.F. and Ching, R.M. (1985). "Influence of SPT procedures in soil liquefaction resistance evaluations," J. of Geotech. Eng. Div., ASCE., 111(12): 1425-1445.

[22]. Tokimatsu, K., and Aska, Y. (1998). "Effects of liquefaction-induced ground displacements on pile performance in the 1995 Hyogoken-Nambu earthquake," Soils and Foundations, Special Issue on Geotechnical Aspects of the January 17, 1995 Hyogoken-Nambu Earthquake, 2: 163-178. [23]. Towhata, I., V. Sesov, R. Motamed, and M. Gonzales (2006), "Model tests on lateral earth pressure on large group pile exerted by horizontal displacement of liquefied sandy ground," Proc., 8th U.S. National Conf. on Earthquake Eng., San Francisco, California, Paper No. 1227. 